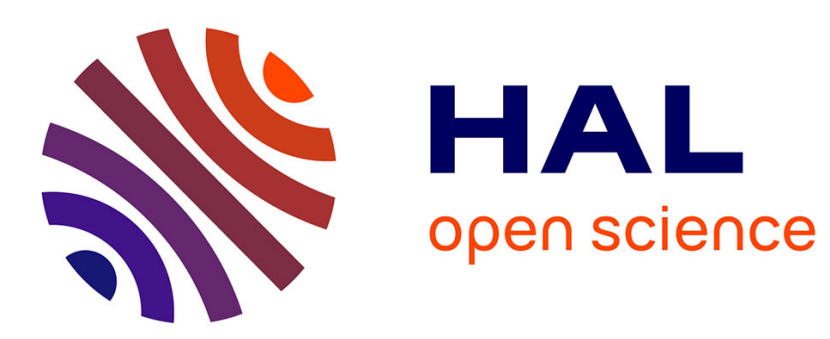

\title{
VOID GROWTH DURING HIGH VELOCITY IMPACT : EXPERIMENT AND MODEL
}

\author{
M. Worswick, B. Wong, R. Pick
}

\section{To cite this version:}

M. Worswick, B. Wong, R. Pick. VOID GROWTH DURING HIGH VELOCITY IMPACT: EXPERIMENT AND MODEL. Journal de Physique IV Proceedings, 1991, 01 (C3), pp.C3-605-C3-612. 10.1051/jp4:1991385 . jpa-00250530

\section{HAL Id: jpa-00250530 https://hal.science/jpa-00250530}

Submitted on 1 Jan 1991

HAL is a multi-disciplinary open access archive for the deposit and dissemination of scientific research documents, whether they are published or not. The documents may come from teaching and research institutions in France or abroad, or from public or private research centers.
L'archive ouverte pluridisciplinaire HAL, est destinée au dépôt et à la diffusion de documents scientifiques de niveau recherche, publiés ou non, émanant des établissements d'enseignement et de recherche français ou étrangers, des laboratoires publics ou privés. 


\title{
VOID GROWTH DURING HIGH VELOCITY IMPACT : EXPERIMENT AND MODEL
}

\author{
M.J. WORSWICK*, B. WONG** and R.J. PICK ${ }^{* * *}$ \\ * Carleton University, ottawa, ontario, K1S 5B6, Canada \\ * Atomic Energy of Canada Ltd., Mississauga, Ontario, L5K 1B2, \\ Canada \\ *** University of Water1oo, Waterloo, Ontario, N2L 3G1, Canada
}

résumé : La croissance de cavité en Impact de Taylor symétrique de cylindres en laiton a été déterminée expérimentalement. les porosités mesurées ont été comparées aux prévisions utilisant un modèle de comportement basé sur la fonction d'écrouissage de Gurson [1], introduite dans le code DYNA3D. les résultats des calculs sont en accord avec les expériences et permettent de prévoir avec précision le développement de zones poreuses dans les cibles impactées.

\begin{abstract}
The void growth during symmetric Taylor cylinder impact tests on free cutting (leaded) brass has been determined experimentally. The measured porosities have been compared to predictions using a constitutive model based on the Gurson [1] yield function, implemented within the DYNA3D finite element code. The predictions compare favourably with experiment and accurately predict the development of porous zones within these impact specimens.
\end{abstract}

\section{1.-Introduction}

Ductile fracture occurs within plastically deforming metals through the nucleation, growth and coalescence of small voids to form a crack. This mechanism is operative under high strain rate conditions in problems involving impact [2] and explosive forming [3].

This paper examines the application of the Gurson constitutive model to predict the onset of ductile fracture under high strain rate deformation. Numerous investigations have shown that this model provides reasonable predictions of porosity evolution and constitutive softening due to porosity under quasi-static loading [4]. The application of this model to inertial conditions has received only limited attention [5]; however, recent work by Dumont et al. [6] suggests that the rate of increase in void volume fraction with applied plastic strain is not substantially altered by strain rate.

\section{2.-Experiment}

Symmetric Taylor cylinder impact experiments were performed on UNS C36000 Free Cutting Brass. This material is an alpha brass containing $2.5 \%$ dispersed lead phase added to improve machinability. The application of a suitable annealing process [4] results in the lead phase forming into spheroidal particles with a mean aspect ratio of unity. For the purposes of the current study, these lead particles serve as void nucleation sites since the low strength lead phase readily bursts during tensile plastic deformation. The volume fraction of lead particles was adopted as the initial porosity level and, using standard quantitative metallographic techniques, was determined to be 0.025 with a standard deviation of 0.008 .

In the symmetric Taylor cylinder test, a $34.7 \mathrm{~mm}$ long, $18 \mathrm{~mm}$ diameter cylinder impacts an identical stationary cylinder at a velocity in the range $175-300 \mathrm{~m} / \mathrm{s}$. During the impact, noticeable mushrooming and barreling of the cylinders occurs, causing the development of a zone of tensile hydrostatic stress along the specimen axis, just below the impact face. If the impact velocity is sufficiently high, ductile cracking can occur within this zone along the axis (Figure 1). 
The impact velocity and total deformation in Taylor cylinder experiments used to determine material constitutive response are limited by the onset of cracking along the specimen axis. In the current study, the cracking phenomena is of primary interest and the Taylor test provides a geometry in which an isolated region of tensile plastic deformation exists within a predominantly compressively loaded specimen. The

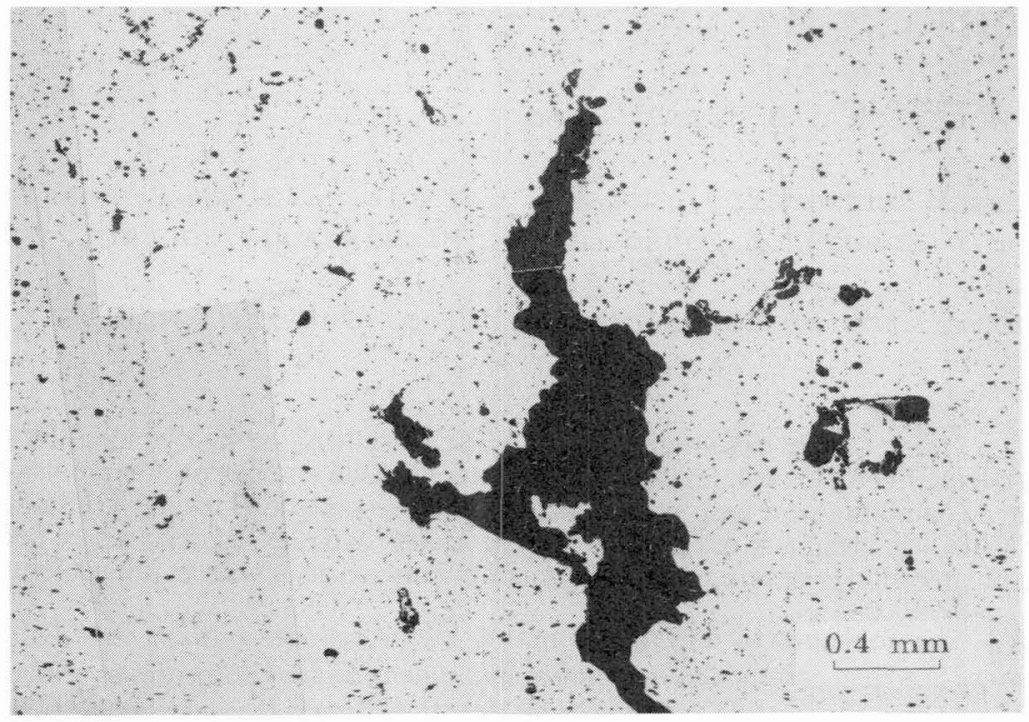

Figure 1: Optical micrograph showing cracking along the axis of a brass Taylor cylinder impacted at 300 $\mathrm{m} / \mathrm{s}$ (symmetric impact). Impact face lies along the bottom of the micrograph.

strain rates are also quite high, exceeding $10^{4} \mathrm{~s}^{-1}$.

In order to determine a suitable impact velocity on which to base comparisons between experimentally determined void growth and model predictions, tests were made with velocities in the range $175-300 \mathrm{~m} / \mathrm{s}$. The recovered specimens were sectioned longitudinally and examined metallographically to determine the extent of void growth. It was determined that an impact velocity of $230 \mathrm{~m} / \mathrm{s}$ provided significant levels of void growth with void coalescence confined to a small region (Figure 2). Impact velocities in excess of this level resulted in increased void coalescence and crack propagation along the axis towards the impact face (Figure 1).

Seven Taylor cylinder experiments were then performed with recorded impact velocities equal to $230 \pm 1 \mathrm{~m} / \mathrm{s}$. Measurements of void volume fraction were taken at locations along the axis of each cylinder; the measurements at each location were then averaged over all of the cylinders to obtain an averaged distribution. This averaging process was intended to account for the statistical variation in initial porosity within the as-received material [7].

\section{1-Material Properties}

The material stress-strain behaviour was described using a polynomial fit to quasi-static uniaxial tensile data [4]. The flow stress obtained using this fit was then scaled using a log-strain rate relationship:

$$
\bar{\sigma}=\left(94.4+1594 \bar{\epsilon}^{p}-1693\left(\bar{\epsilon}^{p}\right)^{2}+645\left(\bar{\epsilon}^{p}\right)^{3}\right)(1+0.0009 \ln (\dot{\epsilon}))(\mathrm{MPa}),
$$

in which $\bar{\sigma}$ is the material flow stress, $\vec{\epsilon}^{p}$ is the effective plastic strain and $\dot{\epsilon}$ is the effective strain rate. The constant 0.0009 , prior to the logarithmic term, represents the strain rate sensitivity of the material, determined by Wong [7], which is recognised as being small. This correction for strain rate was viewed as 
being somewhat crude; however, brass is not particularly strain rate-sensitive and the predicted cylinder profiles obtained using equation (1) agreed well with experiment.

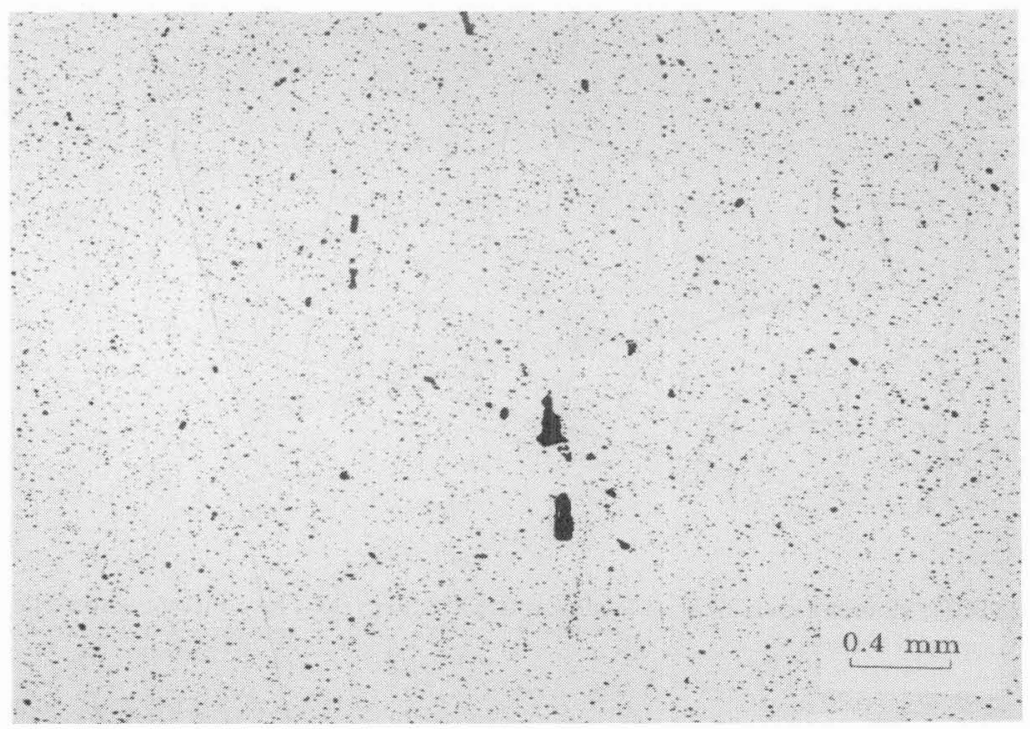

Figure 2: Optical micrograph showing limited void coalescence along the axis of a cylinder impacted at $230 \mathrm{~m} / \mathrm{s}$. Impact face lies along the bottom of the micrograph

\section{3.-Model}

Finite element calculations were performed using the DYNA3D explicit dynamic finite element code due to Hallquist and Whirley [8]. As part of this research, this code was modified to incorporate a Gurson constitutive routine. The problem modelled can be treated as axisymmetric requiring a two-dimensional analysis only; however, the three-dimensional version of DYNA was used since the authors wish to pursue three-dimensional problems in future and wanted to avoid implementing the constitutive model into DYNA2D in addition to DYNA3D.

Note that a symmetric impact can be modelled using only one cylinder impacting a rigid, frictionless wall at one-half the velocity of the symmetric impact. In addition, only one-quarter of the cylinder was modelled with symmetry conditions applied along the $x=0$ and $y=0$ planes (Figure 3 ). These simplifications were adopted since they substantially reduced the computational effort required.

The initial undeformed finite element mesh is not shown; however, Figure 3 shows the deformed mesh $100 \mu \mathrm{s}$ after a symmetric impact at $230 \mathrm{~m} / \mathrm{s}$. Eight node hexagonal elements were used, the number of elements used along the cylinder axis and radius were 31 and 8 , respectively. Formal mesh convergence studies were not performed, although the results from this calculation agreed well with results obtained using 40 by 12 elements.

\section{1-Constitutive Model}

The elastic response of the cylinder was modelled using Hooke's Law for a linear elastic isotropic material. The macroscopic plastic response was modelled using the Gurson [1] constitutive model for porous continuum plastic materials. Central to this model is the use of the Gurson yield function to determine conditions to initiate or sustain plastic flow within a plastically dilating porous solid:

$$
\phi=\left(\frac{\Sigma_{e q}}{\bar{\sigma}}\right)^{2}+2 f q_{1} \cosh \left(q_{2} \frac{3 \Sigma_{h y d}}{2 \bar{\sigma}}\right)-1-q_{3} f^{2}=0
$$




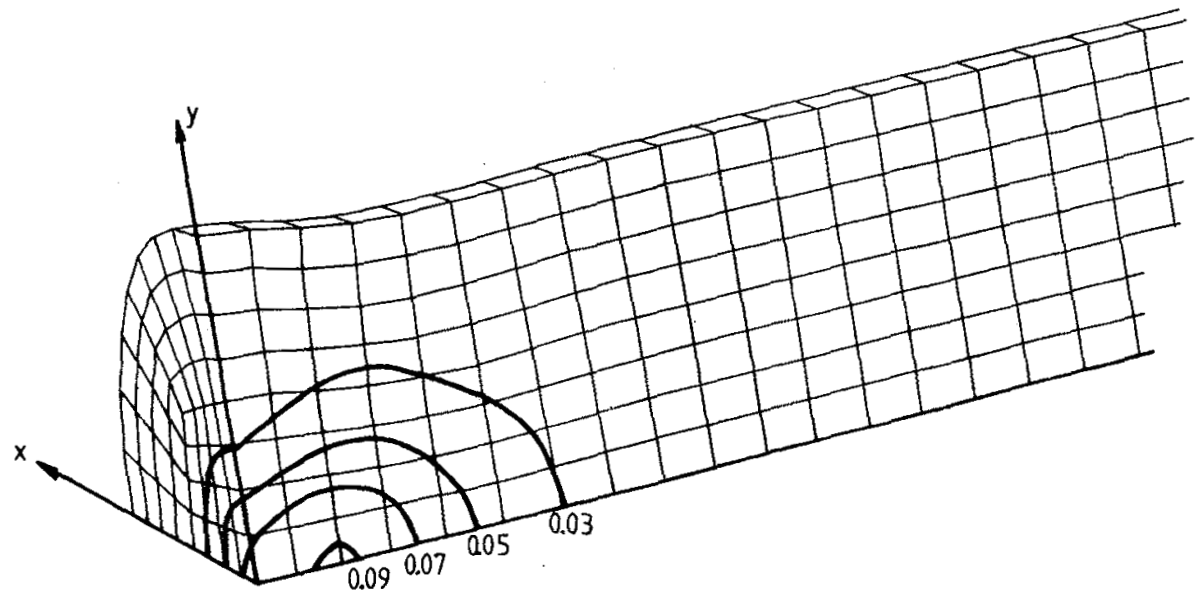

Figure 3: Deformed finite element mesh $100 \mu \mathrm{s}$ after impact at $230 \mathrm{~m} / \mathrm{s}$. The contours show the distribution of predicted void volume fraction.

in which $f$ is the void volume fraction and $\Sigma_{e q}$ is the equivalent stress, defined by $\Sigma_{e q}^{2}=3 / 2 \Sigma_{i j}^{\prime} \Sigma_{i j}^{\prime}$, with $\Sigma_{i j}^{\prime}$ being the deviatoric components of $\Sigma_{i j}$. $\Sigma_{k y d}$ is the hydrostatic component of stress, given by $\Sigma_{h y d}=1 / 3 \Sigma_{k k}$. The coefficients $q_{1}, q_{2}$ and $q_{3}$ are "calibration" coefficients introduced by Tvergaard [9] to better represent the effects of porosity in plastically deforming materials. The values adopted were $q_{1}=$ $1.25, q_{2}=0.95$ and $q_{3}=q_{1}^{2}$, given by Worswick and Pick [10].

Using equation 2 as a flow potential and applying the normality condition [1], one obtains:

$$
\dot{\epsilon}_{i j}^{p \infty}=\frac{1}{H}\left(\frac{3 \Sigma_{i j}^{\prime}}{2 \bar{\sigma}}+\alpha \delta_{i j}\right)\left(\frac{3 \Sigma_{k l}^{\prime}}{2 \tilde{\sigma}}+\alpha \delta_{k l}\right) \dot{\Sigma}_{k l}
$$

where

$$
\alpha=\frac{f}{2} q_{1} q_{2} \sinh \left(q_{2} \frac{3 \Sigma_{\text {hyd }}}{2 \bar{\sigma}}\right)
$$

and

$$
H=\frac{h}{1-f}\left[\left(\frac{\Sigma_{e q}}{\bar{\sigma}}\right)^{2}+\alpha \frac{3 \Sigma_{h y d}}{\bar{\sigma}}\right]^{2}-3 \bar{\sigma} \alpha(1-f)\left[q_{1} \cosh \left(q_{2} \frac{3 \Sigma_{h y d}}{\bar{\sigma}}\right)-q_{3} f\right] .
$$

The term $h$ is the slope of flow stress versus effective plastic strain curve (equation 1 ) and $\delta_{i j}$ is the Kronecker Delta. The components of plastic strain, $\epsilon_{i j}^{p \infty}$, refer the macroscopic strains rather than the detailed distributions near individual voids.

Using work equivalence, the effective plastic strain rate in the matrix, $\dot{\bar{\epsilon}}^{p}$, is given by

$$
\dot{\bar{\epsilon}}^{p}=\frac{\Sigma_{i j} \dot{\epsilon}_{i j}^{p \infty}}{(1-f) \bar{\sigma}} .
$$

The rate of increase in porosity will be due to the growth of existing voids and the nucleation of new voids,

$$
\dot{f}=\dot{f}_{\text {growth }}+\dot{f}_{\text {nucleation }}
$$

The growth of existing voids is given by

$$
\dot{f}_{\text {growth }}=(1-f) \dot{\epsilon}_{k k}^{p \infty},
$$

since the matrix material is assumed to be incompressible and $\dot{\epsilon}_{k k}^{p \infty}$ is due purely to void expansion.

Void nucleation is modelled as plastic strain-controlled. It is assumed that voids nucleate at second phase particles and that there will be a statistical variation in the nucleation strain for individual particles. 
Assuming that the nucleation strain for the total population of particles follows a normal distribution, one can use the following equation adopted by Gurson [1]:

$$
\dot{f}_{\text {nucleation }}=A h \dot{\epsilon}^{p},
$$

where

$$
A=\frac{1}{h} \frac{f_{N}}{S_{N} \sqrt{2 \pi}} \exp \left[-\frac{1}{2}\left(\frac{\bar{\epsilon}^{p}-\epsilon_{N}}{S_{N}}\right)^{2}\right] .
$$

The term $f_{N}$ represents the volume fraction of void nucleating particles while $\epsilon_{N}$ and $S_{N}$ are the average and standard deviation of the strains at which the particles nucleate voids. In free cutting brass, the globular lead phase would constitute the void nucleating particles.

Equations (2) through (10) combine to describe a constitutive model for the evolution of porosity during plastic deformation and the reduction in material load-carrying capacity, referred to as constitutive softening. This set of equations was implemented as a Gurson constitutive routine in DYNA3D.

A subincrement, elastic predictor-normal corrector scheme was used to integrate equations (2) through (10). This scheme was adopted to allow for the severe pressures, high strain rates and large incremental strains occurring during impact loadings. Each strain step was divided into one or more subincrements. Each strain subincrement was then integrated by first calculating a trial or predictor stress, $\Sigma^{\text {trial }}$, by assuming that the entire subincrement was elastic. The number of subincrements was chosen automatically to keep the elastic predictor stresses "close" to the yield surface. If the subincrement is plastic, given by $\phi>0$ in equation (2), then the stresses are returned to the yield surface along the yield surface normal, $\partial \phi / \partial \Sigma_{i j}$. An iterative solution is used for the normal return due to the non-linear nature of equation (2). Note that although complicated by the non-linear nature of the Gurson yield surface, the stress integration scheme used herein is analogous to the elastic predictor-radial corrector scheme commonly used in Mises yield surface calculations.

The initial void volume fraction was modelled as zero and the volume fraction of void nucleating particles, $f_{N}$, was set equal to the volume fraction of lead particles, 0.025 . Based on observations by Worswick and Pick [4], the average strain and standard deviation to nucleate voids, $\epsilon_{N}$ and $S_{N}$, were set equal to 0.13 and 0.05 , respectively.

\section{4.-Results}

Figures 1 and 2 are optical micrographs taken along the axis just back from the impact face of cylinders impacted at 300 and $230 \mathrm{~m} / \mathrm{s}$. The micrographs show the increase in porosity within this region. Some isolated void coalescence was observed in the specimens impacted at $230 \mathrm{~m} / \mathrm{s}$. The amount of void coalescence and extent of the porous zone increased with impact velocity until crack formation and propagation occured through a void coalescence mechanism (Figure 1). Void coalescence occurred through localized shearing between voids and was transgranular (Figure 4).

The distribution of porosity along the axis of the cylinders impacted at $230 \mathrm{~m} / \mathrm{s}$ is shown in Figure 5 . Despite the large scatter in the data, it is observed that the cylinders are subjected to compressive stresses throughout most of their interior. The mushrooming of the cylinder produces high hydrostatic stresses just behind the impact face on the axis, causing the development of a relatively small porous zone. Figure 5 shows a large increase in porosity occuring within the porous zone with peak mean porosity levels of over $15 \%$.

Figure 6 plots the predicted stress triaxiality, $\Sigma_{h y d} / \bar{\sigma}$, versus time history for an element at the centre of the porous zone. During the initial shock loading, the triaxiality is compressive and reaches -38 . This is followed by a high tensile triaxiality stress state in the period $2-5 \mu$ s during which the projectile begins to mushroom, the peak triaxiality reaching 5.24. This value is extremely high, particularly when one considers that the triaxiality ahead of a blunting crack tip is around 4 [11] and that the rate of void growth is known to be an exponential function of triaxiality [12]. The corresponding predicted porosity history is also plotted and shows the dependence of void growth rate on triaxiality as the rate of increase of porosity is very high over the short duration of tensile stress triaxiality. Void closure occurs during the period 7-10 $\mu$ s due to compressive loading experienced during this period. The predicted strain rates 


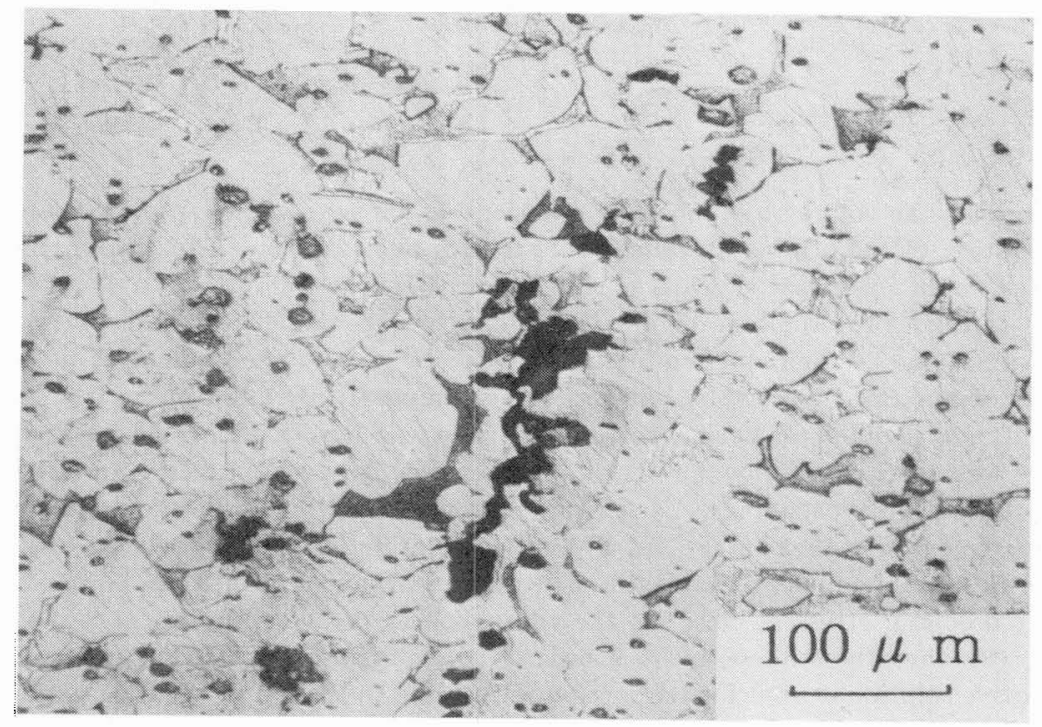

Figure 4: Optical micrograph showing a cluster of coalesced voids near the impact face of a cylinder impacted at $267 \mathrm{~m} / \mathrm{s}$.

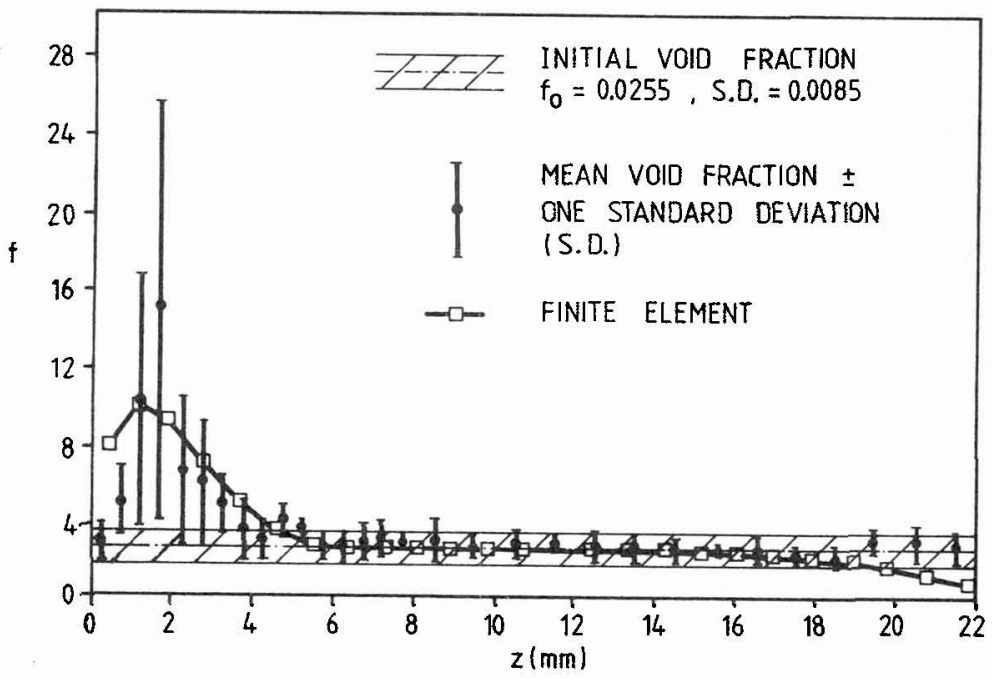

Figure 5: Measured porosity distribution along specimen axis. Impact velocity $=230 \mathrm{~m} / \mathrm{s}$. The scatter bands indicate one standard deviation from measurements on seven specimens. The solid curve shows the predicted porosity distribution. 


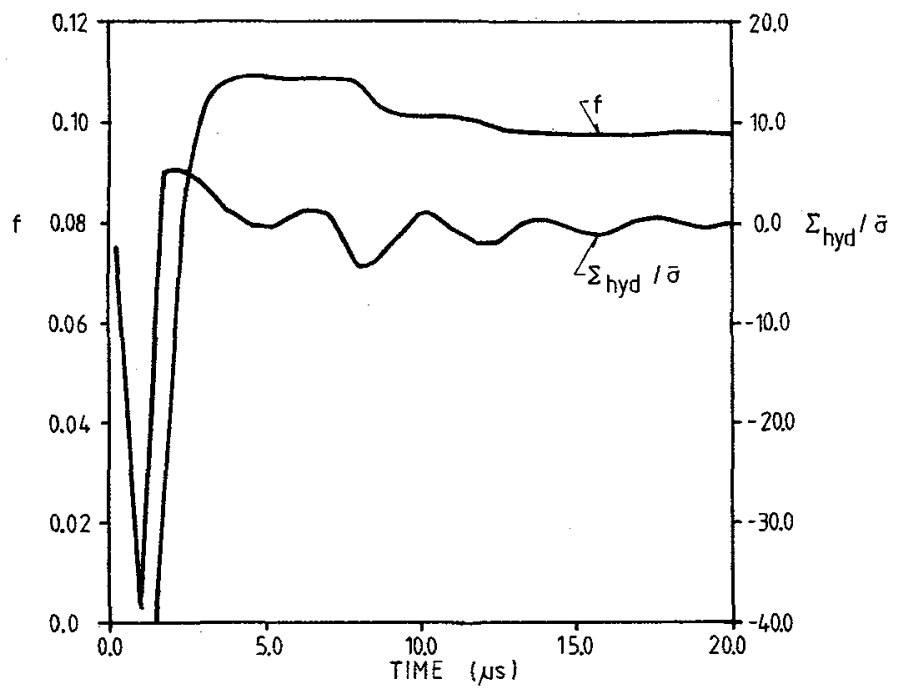

Figure 6: Time histories of porosity and triaxiality at the centre of the porous zone for an impact velocity of $230 \mathrm{~m} / \mathrm{s}$.

peaked at $6 \times 10^{4} \mathrm{~s}^{-1}$ and decayed to $4 \times 10^{3} \mathrm{~s}^{-1}$ over $20 \mu \mathrm{s}$. The majority of the void growth occurs during the first $5 \mu$ s of the impact and is completed within $20 \mu \mathrm{s}$.

Comparison between the measured and predicted porosity distributions is shown in Figure 5 . The peak predicted porosity level is lower than the measured value; however, the model does capture the distribution in porosity within the specimen quite well as seen in Figure 5 and also in Figure 3, in which contours of void volume fraction are plotted.

The effect of impact velocity on porosity evolution is shown in Figure 7 which plots predicted porosity distributions for impact velocities of 175,230 and $300 \mathrm{~m} / \mathrm{s}$. There is a marked increase in porosity within the porous zone with increased impact velocity. At an impact velocity of $300 \mathrm{~m} / \mathrm{s}$, the predicted porosity at the impact face has reached levels at which void coalescence would occur as was observed experimentally. The addition of a model incorporating void coalescence would permit simulation of the observed crack formation and growth. No void coalescence was observed in the cylinders impacted at $175 \mathrm{~m} / \mathrm{s}$ for which the predicted porositites only reached 0.08 .

\section{5.-Discussion}

The void coalescence observed in the experiments was not considered by the model. Regions of coalesced voids would exhibit porosities higher than that due to void nucleation and growth and their existence would partially account for the measured porosities lying above the predicted values. The prediction of void coalescence will be addressed in future work.

One interesting aspect of the current work is the realization that extremely high tensile triaxial stress states can exist under inertial loading conditions. In the Taylor test, the level of triaxiality was well in excess of that ahead of a blunting crack tip; one would also expect high triaxiality levels in problems involving spallation. This high level of triaxiality, coupled with the large strain increments associated with high strain rate problems, necessitates robust numerical schemes to accurately integrate the constitutive equations. Studies underway have determined that simple forward-Euler integration schemes are often unstable for this class of yield function due to an inability to remain on the yield surface. The current scheme suffers from similar instabilities if the number of subincrements used is inadequate. Clearly, there exists room for further development of more reliable integration schemes for such constitutive models. 


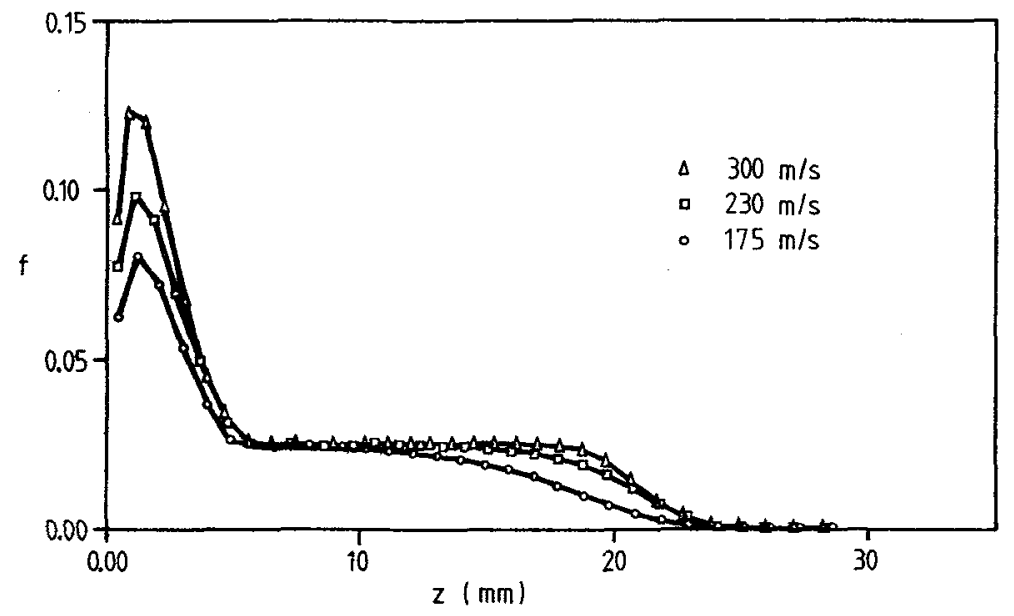

Figure 7: Predicted porosity distribution along cylinder axis for impact velocities of 175,200 and $300 \mathrm{~m} / \mathrm{s}$.

\section{6.-Summary}

The predicted and measured porosity levels and distributions in the Taylor cylinders compared well, lending confidence to the use of Gurson-based constitutive models in problems involving inertial and high strain rate conditions. Similarly good agreement was obtained by Johnson and Adessio [5] in Gurson-based simulations of plate impact phenomena. There exists a requirement, however, for more controlled experiments in which strain rates and triaxiality levels are held nearer to constant levels. The tensile Hopkinson bar experiment is currently being studied in an attempt to achieve void growth rate measurements under such controlled conditions.

\section{Acknowledgements}

Financial support for this work was provided to R.J. Pick and M.J. Worswick from the Natural Sciences and Engineering Reseach Council of Canada and the Defence Research Establishment Suffield.

\section{References}

[1] Gurson,A.L., PhD Thesis, Brown University, 1975.

[2] Curran,D.R., Seaman,L. and Shockey,D.A., Phys. Rep., March, 1987.

[3] Worswick,M.J., Qiang,N., Niessen,P. and Pick,R., EXPLOMET 90, University of California, San Diego, August 12-17, 1990.

[4] Worswick,M.,J. and Pick,R.J., accepted for publication in J. Appl. Mech., 1990.

[5]. Johnson,J.N. and Adessio,F.L., J. Appl. Phys., 64, pp. 6699-6712, 1988.

[6] Dumont,C. and Levaillant,C., EXPLOMET 90, University of California, San Diego, August 12-17, 1990.

[7] Wong,B.J., PhD Thesis, Department of Mechanical Engineering, University of Waterloo, Canada, 1990.

[8] Hallquist,J.O. and Whirley,R.G., DYNA3D Users Manual, Lawrence Livermore National Laboratory, UCID-19592, Rev. 5, 1989.

[9] Tvergaard,V., Int. J. Frac., 17 pp. 389-407, 1981.

[10] Worswick,M.J. and Pick,R.J., J. Mech. Phys. Sol., 38, pp. 601-625, 1990.

[11] McMeeking,R.M., J. Mech. Phys. Sol., 33, pp. 25-49, 1977.

[12] Rice.R.J. and Tracey,D.M., J. Mech. Phys. Sol., 17, pp. 201-217, 1969. 